\title{
Nurses' knowledge, beliefs, attitudes, and practices regarding electronic cigarettes: A cross- sectional study
}

\author{
Quinta Mbe ${ }^{l}$, Olabode Ayodele' ${ }^{1}$ Dorleesa Doss ${ }^{1}$
}

\section{Dear Editors,}

E-cigarette consumption has increased rapidly over recent years, partly due to the belief that the use of e-cigarettes is a potential smoking cessation aid, and harm-reducing alternative to conventional cigarettes ${ }^{1}$. However, evidence is mixed regarding the efficacy of e-cigarettes in smoking cessation ${ }^{2}$. Further, potential harmful health effects of e-cigarettes have been reported, but scientific research is yet to fully examine these effects ${ }^{3}$. In view of the inconsistent conclusions regarding e-cigarette safety, and use as a smoking cessation aid, it is unclear how health professionals, such as nurses, guide their patients about e-cigarette use. We assessed knowledge, beliefs, and practices regarding e-cigarettes among a cohort of United States Midwestern hospital nurses using the theory of planned behavior as a theoretical framework.

A cross-sectional study of nurses recruited through the hospital email system was conducted. An invitation email containing the informed consent, purpose of study, and the survey link was sent out to 200 nurses, who provide preventive care at the family medicine center of the hospital. Of these, 65 responded. The survey (available as supplementary information) measured demographics, knowledge, attitude, subjective norm, perceived behavioral control, and practices regarding e-cigarettes. The survey-questions utilized were adapted from a previous study ${ }^{4}$. Descriptive statistics characterized the study population while correlation analysis assessed associations, using the Statistical Package for Social Sciences (SPSS) Version 24. Ethical approval was sought and granted by the institutional review board, and the participating hospital.

All study participants had heard of e-cigarettes and $61.5 \%$ (see Table 1) reported that they knew nothing or very little about e-cigarettes. About $68 \%$ of the participants first learned about e-cigarettes through media advertisements, other sources reported include patients/ clients $(23.1 \%)$, roadside posters such as billboards (4.6\%), and professional sources, including journal articles and newsletters (4.6\%). Half of the nurse participants were willing to learn more about e-cigarettes. There were mixed responses regarding e-cigarette safety, and efficacy in smoking cessation. About $26 \%$ of them believed e-cigarettes are safer alternatives to conventional cigarettes, and $67 \%$ agreed that e-cigarettes may be a gateway to conventional cigarette use. Support for e-cigarette regulation in public and work places was relatively high $(87.6 \%)$ among the nurses. About $86 \%$ of the respondents believed that e-cigarettes should be regulated like other tobacco products. Only $34 \%$ of the nurses agreed that e-cigarettes are a helpful aid for smoking cessation. A considerable number (61.8\%) of the nurses reported being uncomfortable counselling patients about e-cigarettes. Moreover, $60.3 \%$ indicated that their decision to counsel patients would most likely be influenced by their supervisors/managers and $20.6 \%$ by their co-workers. There was positive and significant correlation between intention to counsel patients, attitude $(r=0.60 ; \mathrm{p}<0.0001)$, perceived behavioral control $(\mathrm{r}=0.41 ; \mathrm{p}=0.001)$, and knowledge $(\mathrm{r}=0.32 ; \mathrm{p}=0.009)$. There was no significant correlation between intention to counsel patients about e-cigarettes and subjective norm.

Future studies must determine the generalizability of our findings due to our limited sample size. However, we have extended previous research studies ${ }^{4-7}$ that have demonstrated low knowledge of e-cigarettes, mixed beliefs about e-cigarette safety, and efficacy as a smoking
AFFILIATION

1 Indiana State University, USA

CORRESPONDENCE TO

Olabode Ayodele. Indiana State University, $400 \mathrm{~N}$ 4th Street,

47809 Indianapolis, USA.

E-mail: olabode.ayodele@

indstate.edu

KEYWORDS

knowledge, smoking cessation,

beliefs, attitude, counseling,

e-cigarette

Received: 3 May 2017

Revised: 4 August 2017

Accepted: 21 August 2017 


\section{Letter to the Editor}

cessation aid among healthcare providers in the USA. Given the critical role of nurses in counseling patients about tobacco cessation, it is important that they provide information based on evidence, not anecdotes or marketing messaging. Professional education and training would help nurses to provide evidence-based guidance about e-cigarette safety, and efficacy in smoking cessation.

Table1. Knowledge, comfort level, and desire to learn about e cigarettes

\begin{tabular}{|c|c|c|}
\hline & $(\mathrm{N}=65$ & $\%$ \\
\hline \multicolumn{3}{|l|}{ How much do you know about e-cigarettes? } \\
\hline Quite a lot & 4 & $6.2 \%$ \\
\hline A moderate amount & 21 & $32.3 \%$ \\
\hline A little & 34 & $52.3 \%$ \\
\hline Nothing at all & 6 & $9.2 \%$ \\
\hline \multicolumn{3}{|l|}{ How did you first learn about e-cigarettes? } \\
\hline Media ads & 44 & $67.7 \%$ \\
\hline Roadside poster (signposts or billboards) & 3 & $4.6 \%$ \\
\hline Patients/clients & 15 & $23.1 \%$ \\
\hline Professional source (journal articles or newsletters) & 3 & $4.6 \%$ \\
\hline \multicolumn{3}{|c|}{ *What percentage of your patients are e-cigarette users? } \\
\hline $0-25 \%$ & 52 & $85.2 \%$ \\
\hline $26-50 \%$ & 9 & $14.8 \%$ \\
\hline \multicolumn{3}{|c|}{ Would you be interested in learning more about e-cigarettes? } \\
\hline Yes & 32 & $49.2 \%$ \\
\hline No & 33 & $50.8 \%$ \\
\hline \multicolumn{3}{|c|}{ How comfortable are you counseling patients about e-cigarettes? } \\
\hline Extremely comfortable & 6 & $9.2 \%$ \\
\hline Moderately comfortable & 7 & $10.8 \%$ \\
\hline Slightly comfortable & 12 & $18.5 \%$ \\
\hline Slightly uncomfortable & 17 & $26.2 \%$ \\
\hline Moderately uncomfortable & 20 & $30.8 \%$ \\
\hline Extremely uncomfortable & 3 & $4.6 \%$ \\
\hline
\end{tabular}

${ }^{*}$ Four participants did not answer the question.

\section{REFERENCES}

1 Regan AK, Promoff G, Dube SR, Arrazola R. Electronic nicotine delivery systems: adult use and awareness of the 'e-cigarette' in the USA. Tob Control 2013, 22(1):19-23. doi: 10.1136/tobaccocontrol-2011-050044

2. Malas, M., van der Tempel, J., Schwartz, R., Minichiello, A., Lightfoot, C., Noormohamed, A., Andrews, J., Zawertailo, L., Ferrence, R. Electronic cigarettes for smoking cessation: A systematic review. Nicotine Tob Res. 2016, 18(10), 1926-1936. doi: $10.1093 / \mathrm{ntr} / \mathrm{ntw} 119$

3. Pisinger C, Dossing M. A systematic review of health effects of electronic cigarettes. Prev Med. 2014, 69:248-260. doi: 10.1016/j.ypmed.2014.10.009

4. Pepper, J.K., McRee, A.L., Gilkey, M.B. Healthcare providers' beliefs and attitudes about electronic cigarettes and preventive counseling for adolescent patients. J Adolesc. Health 2014, 54, 678-683. doi:10.1016/j.jadohealth.2013.10.001
5. Pepper, J.K, Gilkey, M.B., Brewer, N.T. Physicians' counseling of adolescents regarding e-cigarette use. J Adolesc. Health 2015, 57(6):580-586.

doi: 10.1016/j.jadohealth.2015.06.017

6. Kandra, K.L.; Ranney, L.M.; Lee, J.G.; Goldstein, A.O. Physicians' attitudes and use of e-cigarettes as cessation devices, North Carolina, 2013. PLoS ONE 2014; 9(7): e103462. doi: 10.1371/journal.pone.0103462

7. El-Shahawy, O., Brown, R. Lafata, J.E. Primary care physicians' beliefs and practices regarding e-cigarette use by patients who smoke: a qualitative assessment. Int J Environ Res Public Health 2016, 13(5): pii: E445. doi: 10.3390/ijerph13050445
CONFLICT OF INTEREST The authors have completed and submitted the ICMJE Form for Disclosure of Potential Conflicts of Interest and none was reported.

FUNDING

There was no source of funding for this research.

PROVENANCE AND PEER REVIEW

Not commissioned: externally peer reviewed 